\title{
Beyond health and well-being: transformation, memory and the virtual in older people's music and dance
}

\author{
By Kate Wakeling* $\mathcal{E}$ Jonathan CLarK
}

\begin{abstract}
Research exploring older people and the participatory arts has tended to focus on notions of biomedical impact, often coupled with appeals to evasive notions of "well-being." Rather than suggesting such approaches are invalid, this article proposes the need for their extension and proposes an alternative, critical approach to analysing older people's experience of arts participation. Based on ethnographic participant observation and intensive consultation with a cohort of older people engaged in a programme of creative music and dance, we explore the complex processes and possibilities of transformation that the participatory arts can initiate, examining how performance can create intriguing linkages between past, present and future experiences. Taking a phenomenological approach to the study of memory, recollection, reminiscence and future anticipation, we discuss how arts participation can "actualise" potential memories in older participants, examining how and why this kind of expressive activity animates the idea of "virtual" selves (after Bergson).
\end{abstract}

* Kate Wakeling \& Jonathan Clark, Trinity Laban Conservatoire of Music and Dance, London, UK 
International Journal of Ageing and Later Life

Keywords: memory, well-being, temporality, imagined selves, phenomenology, pragmatism, participatory arts.

Participatory arts programmes targeting older people have blossomed in recent years, offering increasingly diverse and colourful opportunities for creative engagement among people aged 60 and over (Cutler 2009). Yet despite this rich array of activity, research into participatory arts activity among older people has been largely restricted to somewhat instrumentalist accounts of health and well-being outcomes. ${ }^{1}$ Whilst the field of critical gerontology has for some time fought against accounts of ageing governed by "biological determinism and the narrative of decline," the majority of ongoing research into older people's arts participation remains focused on impact-driven, biomedical studies (Twigg 2004: 60).

This article presents an alternative approach to the study of older people's arts activity, exploring transformational experiences of memory and anticipation among a cohort of older people engaged in a programme of participatory music and dance. Drawing on ethnographic and phenomenological research methods, we argue that important aspects of older people's experiences of arts activity, particularly concerning more nuanced ideas of temporal perception, have been omitted in contemporary literature on the subject. Rather than suggesting that such studies are invalid, this article demonstrates how these approaches require further extension through a type of methodological switch. This revised methodology, whilst acknowledging the biomedical and psychological benefits of arts activity for older participants, takes a phenomenological approach to the theme. We approach the study of memory, recollection, reminiscence and future anticipation among older people via theoretical constructions concerning the temporality of experience, as provided by classical phenomenology. We furthermore couple this theoretical account with

${ }^{1} \mathrm{~A}$ number of substantial longitudinal studies and literature reviews explore evidence-based health and well-being outcomes of arts participation among older people, including Castora-Binkley et al. (2010), Cohen (2006), Cohen et al. (2007), Connolly and Redding (2010), Cutler (2009), McLean (2011), Noice et al. (2014), Skingley and Vella-Burrows (2010), and Stuckey and Nobel (2010). 
more contemporary accounts of "enacted" and "embodied" cognition. Specifically, we will be interested in how older people's experience of the participatory arts invokes particular linkages between ideas of past, present and future that fall into three overlapping categories: recollection, trait and "virtuality." Firstly, we consider standard phenomenological approaches to recollection, which can be summarised, in a Husserlian vein, as the intentional re-enaction of a past perceptual scene, and the "vicarious simulation" (Thompson 2010) of that scene in the present. Secondly, we will introduce a concept from psychoanalytic metapsychology, that of trait, to show how arts participation can create unexpected linkages between present and past experience triggered by certain types of perceptual and multimodal fragments that in turn act as markers for experiences in the past that had a certain type of affective intensity, and which are recalled through action of the trait (Leclaire 1998). Traits, which can be encountered in the arts participation through highly random and contingent encounters, can adduce layers of memory that a participant may be unaware of, through a process of "unconcealment." Thirdly, we use Bergson's (1990 [1896]) theory of the virtuality of temporal perception, coupled with an extended version of more recent research on "possible selves" (Markus \& Nurius 1986), to show how arts participation among older people not only creates forms of potentiality for subjective identities in the present and future but also acts as a causal agent in the construction of "virtual past selves," generated via the formation of "ideal" memories.

Our research is underpinned by fieldwork examining a series of creative dance and singing sessions with people aged 60 and over, organised through the learning and participation programme of a large conservatoire of music and dance. Carried out over 16 months, this fieldwork combined ethnographic "participant observation" with a phenomenological analysis of group discussion and interviews, alongside a personal diary project undertaken by participants. These fieldwork findings are intertwined with more theoretical material from phenomenological philosophy, and an overarching narrative is formed which connects the phenomenological tradition with the pragmatist philosophy of William James and John Dewey. The key here is that the transexperiential connections and networks which are created through enacted participation in such music and dance sessions are highly "meaningful" considered under a pragmatist 
International Journal of Ageing and Later Life

rubric, which gives an account of "meaning" that stresses its somatic, rather than its conceptual or propositional roots (Johnson 2008). It is specifically this account of this particular form of "meaningfulness," and hence benefit, of arts participation that is missing in alternative approaches that solely stress "health and well-being" improvements among older participants.

The article is structured into three sections. In the first, we give an extensive account of existing research into ideas of well-being "enhancement" through arts activity with older people and contrast these approaches with the argument outlined above. In the second, we give a reading of possible links between the phenomenology of subjective memory and topics derived from other disciplines within the human sciences, such as psychoanalysis, psychology and gerontology, drawing closely on the researchers' participant observation and intensive consultation with the programme's participants. In the concluding discussion, we consider the more general problem of ethics. How should the beneficial effects of arts participation for older people be appropriately captured? How can these events be financially sustained in a climate of austerity, and within a funding environment that idiomatically demands the production of quantitative evidence in return for investment?

\section{Current Approaches to Older People's "Well-Being"}

Alongside a continuing emphasis on the biomedical impact of older people's arts participation, the capacity of the arts to specifically enhance the well-being of older people has been subject to increased investigation and recent years have seen a number of large-scale evidence reviews produced (Cutler 2009; McLean 2011; Noice et al. 2014). Application of the term "well-being" in contemporary impact studies ranges from closelytheorised accounts of "subjective well-being" (Creech et al. 2013; Laukka 2006) to approaches which more readily align with the literature of "successful ageing" in their combination of psychosocial and biomedical factors (McLean 2011). Other studies focused on well-being struggle to situate the term or indeed dispense with defining it altogether (Lally 2009; Ruokonen \& Ruismäki 2011). The following section explores the continued use of this fluid notion of well-being, examining its application in the 
social sciences as a whole, its use in more recent gerontological studies, and lastly, its continued valency in the study of arts activity among older people.

\section{Defining Well-Being among Older People}

Researchers on the topic of well-being have remarked there are as many definitions of "well-being" and "quality of life" measures as the number of people studying the phenomenon (Baker \& Intagliata 1982, cited in Wiggins et al. 2007). Well-being thus remains a contentious idea in terms of both its codification and measurement, and the term is conceptualised very differently across different academic disciplines. Economic studies exploring subjective well-being have tended to employ a "hedonic" approach, examining (and quantifying) both pleasure and the avoidance of pain (see, for instance, Huppert et al. 2009). However, studies rooted in psychology have developed alternative measures, judging there to be a number of limitations to the hedonic model, including the observation that the acquisition of material goods, often deemed a source of pleasure, tends not to equate to increased levels of happiness more generally (Ryan et al. 2008; Vittersø 2004). Instead, many psychologists have tended to favour a "eudaimonic" perspective, a concept drawn from Aristotle that combines sensations of satisfaction and virtue, but is, as summarised by Ryff and Singer (2008: 13), "a term that is simultaneously difficult to spell, to pronounce and to understand". Whilst certainly a slippery concept, the eudaimonic approach to wellbeing tends to focus on "meaning and self-realisation" and considers the degree to which a person is "fully functioning," often through the study of such characteristics and sensibilities as autonomy, determination, interest and sense of fulfilment and hope (Aspinwall \& Standinger 2003; AtecaAmestoy \& Ugidos 2013; Peterson \& Seligman 2004; Ryan \& Deci 2001; Shmotkin 2011).

The shift in demographics manifest through Western Europe's ageing population has placed a growing emphasis on the needs and concerns of older people, including a requirement to address fully the question of sustaining and enhancing older people's well-being. In the public arena, discussion of this population growth has often invoked disquieting images of "time bombs" or "tsunamis," but has also prompted an increasingly 
International Journal of Ageing and Later Life

vocal movement towards revising such representations of older people, with studies seeking to highlight the wealth of possibilities and opportunities offered by ageing populations (Lloyd-Sherlock et al. 2012). In line with such revisions, researchers have noted the need for well-being research that examines the specific priorities and concerns of older people and which addresses the freedom and opportunity retirement often now brings (Gilleard \& Higgs 2000; Vincent 2003). A number of scales and measures have accordingly been created which are regularly used in research into older people's quality of life and well-being. These include the "CASP-19" self-enumerated scale (Hyde et al. 2003) aimed at measuring "quality of life" and which derives from an explicit theory of human needs (see Doyal \& Gough 1991) to span four domains of life, namely control, autonomy, self-realisation and pleasure; the extension of 1991 World Health Organization Quality of Life (WHOQOL-100) questionnaire, a cross-culturally comparable quality of life assessment instrument which was further developed in 2005 to enhance its application among older people (Power et al. 2005); and the Older People's Quality of Life (OPQOL) questionnaire which was developed in 2009 as a psychometric test to examine multi-dimensional "quality of life" in older people and which derives from the views of older people themselves (Bowling et al. 2009).

A number of researchers have further challenged the prevailing methodologies used in measuring well-being and quality of life among older people. Researchers have noted the so-called "well-being paradox," constituted when "objectively negative" factors are shown to have relatively little effect on subjective quality of life (Mroczek \& Kolarz 1998). McFadden's (2010) gerontological work on the impact of creative engagement on the lives of older people has identified the familiar concept of resilience as a particularly fruitful object of study among older people, suggesting that this term provides a "lived example" of the "well-being paradox". Shmotkin (2011) has similarly addressed the apparent contradiction within self-evaluating well-being studies and proposes the need for a more dynamic, responsive understanding of well-being. The author puts forward a new conceptual model of "the pursuit of happiness in the face of adversity," which considers subjective well-being as an "active agent of adaptation" (Shmotkin 2011: 27). 
Beyond health and well-being

\section{Older People's Well-Being and the Participatory Arts}

Subjective well-being remains a key index in investigating the efficacy of arts activity among older people. Whilst a number of studies have drawn rigorously on gerontological and psychological advances in the field of well-being, a survey of the literature also reveals an array of sometimes disparate and underdetermined conceptualisations of the term and its associated dimensions. Alongside debates concerning the contribution of "sense of identity" and "social interaction" in constructing well-being, a number of studies have explored the notion of "meaning" as a core aspect of subjective well-being, as are outlined below. Discussion of such "meaningmaking" tends to be similarly under-theorised, with limited attention given to the precise processes as to how and why "meaning" might be constructed and its implications for participants' experiences of such activities.

Several arts intervention studies in the field dispense altogether with clarifying the term well-being in their analyses. An insightful study by Lally (2009) on a community singing programme for older people is refreshingly honest about the term: "while the concept of 'well-being' was central to the aims of Sweet Tonic, it remained a vague and fuzzy concept" (Lally 2009: 26). In a study of musical activity among older people, Ruokonen and Ruismäki (2011) note similar challenges of definition, describing the concept as "broad and also very subjective," before going on to outline a loosely eudaimonic approach to the term, where well-being is framed as "a subjective feeling ... related to mood, particularly happiness" (Ruokonen \& Ruismäki 2011: 341).

Some studies offer more rigorously theorised approaches to the topic. The Institute of Education's substantial "Music for Life" research project investigated the impact of music-making on well-being among older people, noting that "there has been little research exploring the potential for music-making to make a significant contribution to the quality of life of older people" (Hallam et al. 2011: 2). In response, the project was founded on a closely structured conceptualisation of well-being, including the CASP well-being scale (Hyde et al. 2003; Wiggins et al. 2007), to generate three key factors as comprising "subjective well-being" among older people: the first related to having a positive outlook on life (purpose), the second to lack of autonomy and control (autonomy/control), and the third to positive social relationships, competence and a sense of recognised 
International Journal of Ageing and Later Life

accomplishment (social affirmation) (Creech et al. 2013: 95-96). In a similar vein, Laukka's (2006) study of the effects of music listening on older people's well-being also divides the concept into three carefullydefined areas: affective well-being, life satisfaction and eudaimonic wellbeing, with each measure based on a standardised codes, including the Positive and Negative Affect Schedule (Watson et al. 1988) and Ryff's (1989) Scale of Psychological Well-Being.

A number of art intervention studies working with older people place the notion of "identity" as central to the concept of well-being. Taylor (1987) describes the "identity crisis" that can emerge out of the loss of work status, which in turn leads to diminished perceptions of well-being. To counter this effect, Taylor (1987: 13) advocates the visual arts as a means by which older adults maintain access to "limitless possibilities". Dabback's (2008) study of older people participating in a band draws on theories of identity grounded in the work of Marcia (1966) and Erikson and Erikson (1997). In response to the potential loss of identity occurring through the retirement transition, musical participation was found to facilitate a "strong identity commitment" among participants, in turn eliciting "well-being and a sense of purpose" (Dabback 2008: 282). In an extension of the "Music for Life" research project outlined above, Creech et al. (2014) explore the notion of subjective well-being via ideas of "identity," through imagined conceptualisations of self. Creech draws on Markus and Nurius' (1986) concept of "possible selves" which refers to an individual's imagined selves, desired or dreaded, which in turn may act as incentives or disincentives for certain kinds of behaviour in an individual. Creech's study describes how participative music-making can act as a medium through which older people may develop "possible musical selves" with the potential to contribute to underlying dimensions of subjective well-being.

It is interesting to note an increasing focus on the idea of locating "meaning" and participating in "meaningful activity" as core dimensions to subjective well-being among older people (Bedding \& Sadlo 2008; Fisher \& Specht 1999; Jonsson et al. 2001; Sinnott 1998). However, the precise role that such "meaningful" or "meaning-making" activities take in enhancing notions of subjective well-being among older people is not yet well understood (Bedding \& Sadlo 2008; Rudman et al. 1997). As one example, 
a study investigating the "role and meaning" that music plays in enhancing well-being in the lives of a community of older Australian people "[frames] music as a symbol used by people for constructing self-identity [that gives] meanings to experiences and emotions ... [where] participants' narratives of the meaning of music provides them with the ability to construct meaning in their lives" (Hays \& Minichiello 2005: 440, 449).

This process was seen a key contributor in "helping participants maintain a sense of well-being" (Hays \& Minichiello 2005: 443). Yet while the study presents diverse and sensitive research findings, it does not explore theoretically how such meaning-making has occurred, or how and why it might contribute an abstract (and in this case otherwise undefined) sense of "well-being."

Allison's (2010) ethnomusicological study of songwriting in nursing homes directly challenges the widespread lack of investigation into such processes. Allison explores how the creation and performance of music enables institutionalised older people to transcend their increasing physical, cognitive and social restrictions, focusing on the "how and why" of participants' responses to creative activities. Allison (2010) notes how the pioneering work of gerontologist Gene Cohen has left us with a challenge; while the field has generated increasing evidence as to the benefits of creative activities, we remain uncertain to "how creativity fits into late life learning and why it is important" (Allison 2010: 276). In answer to this lack of scholarly attention, she advocates the use of ethnographic approaches, highlighting the need for methodologies better able to respond to the "inherently subjective questions" of "process and meaning" (Allison 2010: 277).

In part, this article seeks to answer Allison's call, presenting an alternative approach to investigating and conceptualising the workings of participatory arts activity among older people. While the various impact studies listed above offer valuable and much-needed advocacy as to the positive effects of the arts, we identify, in line with Allison's study, a paucity of critical examination which actively unpicks the more complex and nuanced processes at play in such activity (and the concomitant experience and construction of "meaning"), particularly as voiced by older participants themselves. Whether "subjective well-being" is invoked as a hazy and apparently self-evident concept or is more rigorously codified, 
International Journal of Ageing and Later Life

it tends to invite somewhat instrumentalist and bounded accounts of arts participation which, as our research finds, may neglect the more complex, transexperiential processes potentially sparked by creative activity. Similarly, where notions of "meaning" and "meaning-making" are cited as crucial dimensions to participant experience, studies have tended not to probe further into how or why this meaning-making might occur, or to explore the relationship between arts practice and the construction of such meaning for older participants.

Prompted by participant commentary and extended participationobservation, our research proposes a series of unexpected temporal connections between past, present and future to lie at the heart of many participants' responses to arts activities. In turn, these temporal connections, when viewed through a pragmatist and phenomenological lens, suggest a potent form of "somatic meaning" (Johnson 2008) is created for participants while they are engaged in such activities. This somatic form of meaning resists the more conceptual or propositional senses of the term and so challenges the conventional forms of codification often associated with the definition and measurement of "subjective well-being." In unpicking these processes of temporal perception and somatic "meaning-making" through pragmatist and phenomenological inquiry, we thus hope to bring to light the true complexity and richness at play in participants' experience of arts engagement.

\section{Introduction to the Participatory Groups}

The 'Retired not Tired' programme itself offers weekly singing, creative dance, and combined creative dance and singing sessions for participants aged $60+$, working with c. 100 participants each year. Commentary will focus on two groups from the programme: a creative dance group called "Dance for Health" and a combined music and dance group called "All Singing All Dancing."

"Dance for Health" sessions focus on facilitating creative movement while supporting the associated health benefits of movement to the ageing body. The sessions often begin by focusing on alignment, posture and balance, before then taking these principles into creative movement, often exploring the natural swing or rhythm of the body, and frequently 
involving work in pairs, trios or in larger groups to travel across the space or to devise movement material together. The group has created a number of richly varied performance pieces, including developing improvised responses and co-devising choreographic sequences drawing on Wasily Kandinsky's dynamic painting Swinging (1925) (as discussed below); a playful co-devised work exploring Edwardian etiquette called Barmy on the Crumpet, sparked by an invitation to perform at the Horniman Museum and Gardens as part of their "curious tea party" event; and a series of group-devised pieces focusing on a single body part (e.g. hands, shoulders and feet) which was then developed into an exploratory dance film created by Nicolas Kyprianou.

"All Singing All Dancing" combines music and dance-based activities, woven together by a vocal practitioner and a dance practitioner. Sessions place a strong emphasis on vocal and movement improvisation. Creative content is arrived at through a variety of processes: working from a taught starting point (such as a choreographic sequence or a passage from a pre-written song), working from a co-devised starting point, developing work through improvised content, or working from an individual idea contributed by group members. The group has devised a number of exploratory new creative pieces, including Hear Here (2013) which featured a soundtrack comprised of "home recordings" participants had made of their day-to-day experiences (using recording equipment provided by Trinity Laban) and also featured a poem written and spoken by a group member, which the group then used as the basis from which to devise an extended movement piece. Other performance pieces have drawn on themes of women's suffrage and the pioneering choreography of Isadora Duncan, while I Never Dreamed the Sea so Deep (created across 2013-2014) and saw the development of powerful improvisatory vocal and movement work led by group, inspired by an extract from Allen Ginsberg's poem An Eastern Ballad (as discussed below).

\section{A Phenomenological Approach to Examining Older People's Arts Participation}

The purpose of this section is to examine more critically the intricate experiential qualities of a participatory arts programme for older people, 
International Journal of Ageing and Later Life

notably in terms of temporal perception. Drawing on participant observation and extensive consultation with participants, we explore the intriguing forms of subjective memory occasioned by taking part in creative music and dance, investigating these transformational experiences of temporality from a phenomenological standpoint.

Participant observation was carried out over 16 months, by attending "Dance for Health" and "All Singing All Dancing" sessions weekly, alongside conducting regular semi-structured and informal discussions with participants. In addition, a voluntary 12-week "dance diary" project was conducted with participants from the creative dance class, where volunteers were invited to record personal reflections on each week's session across the term, which were then shared with the researchers at the project's close.

Research findings indicate that the programme provoked a series of potent connections between real and imagined pasts, presents and futures among participants. These connections can be divided into three intersecting categories, which will be discussed in turn: "recollection" as intentional "re-enactment"; the idea of affective "trait" as an unexpected trigger capable of unlocking or "unconcealing" strands of a participant's past; and the notion of "virtual selves," whereby creative participation sparks the construction of both "becoming future selves" and "virtual past selves" through the formation and fusing of "ideal" memories and anticipations. From here, we consider how the discovery of such transformative connections holds powerful implications as to how participants' experiences of arts activity might be more richly and sensitively analysed in the future.

\section{Recollection}

This first linkage between past and present can be categorised as "recollection," drawing on a Husserlian account of temporality. Defined as the reenaction of a past perceptual scene, recollection goes beyond simply recalling a past "that we can grasp and are aware of in some way, as in retention; instead it is explicitly present 'once again', 'anew'" (Bernet 2009: 134).

Participant diary commentary from a "Dance for Health" session aptly captures this sense of embodied re-enactment, where a previous scene is "re-animated" in the present. One participant reflected on an improvised sequence of movement during a creative project responding to Kandinsky's dynamic, colourful painting Swinging (1925). Here, participants were 
invited to respond individually to the lines, circles and spirals featured in the painting as part of an extended group movement improvisation. This particular participant was given a more solo role amidst the group dance, being directed to "activate" the other group members as she span lightly and playfully across the space as the accompanying music came to life. Her diary entry records the powerful sense of "re-enactment" she experienced in developing these movements:

I cannot help becoming like a pulling horse in the opening of the group dance [I] can't identify where this movement comes from except childhood games 'Bell Horses' - pretending to be horses in harness tossing their heads and asserting their freedom. Someone giggled and I tried to stop but could not edit it out.

Through such re-enaction, the past is effectively experienced as another present, the act of recollection affirming "the difference and the identity of two presents that are intimately united despite the temporal difference between them" (Bernet 2009: 136).

Research findings also corroborated the claim that that this type of temporal or horizontal merging constituted a pleasurable and/or potent experience for participants. In one "All Singing All Dancing" session, participants were asked by facilitators to create a pose accompanied by a vocal sound that expressed a "passionate" memory of some kind (which did not need to be disclosed). Responses to the activity proved mixed but powerful. One participant interrupted the task in some distress, stating that she disliked the sensation the activity had aroused in her, asking "what is this meant to do for us? ... I don't want to go back into the past. I want to go forward - to think about the future." Other group members felt differently however, with one stating (in a neat summary of Husserlian recollection): "This is not just about the past. You have to take something from the past and take it out of context - lift it to the future. This is about using an element like that, a memory, and bringing it to life." Further informal discussion demonstrated that some participants found the recollection of such sensations, often linked to childhood, to be a particularly pleasurable element of participating in the group:

[the sessions] remind me in a way of when I was young. [Then] I was free and wasn't worrying about things - and as adulthood came I felt restricted with partners, friends, 
International Journal of Ageing and Later Life

criticism and so you become very restricted with your movement and your voice and everything. This class is like going back on a journey to when I was young, free and frivolous.

To which another participant responded:

following on from this 'going back into childhood' thing ... as we get older and our shapes change there's a sort of self-consciousness ... so I think maybe coming here, it's more to do with how we feel within, not how we are perceived or even how we look but the feelings that it evokes, which can be, as V said, quite sort of light and from days when we were more physically able - it echoes that doesn't it, that sort of freedom of movement.

Here, the re-enaction of past perceptual scenes through voice and movement was indicated by participants to be highly significant, connecting individuals to prior sensations which sparked pleasurable and/or potent feelings, through the creation of transexperiential linkages between past and present.

\section{Traits}

More unexpected linkages between past and present can be identified in participant experience through reference to psychoanalytic metapsychology and the idea of "traits." Again, traits constitute certain types of transexperiential linkages between present and past experience, but they have a phenomenology different from recollection. The theory of traits finds its most recent exposition in the work of psychoanalyst Serge Leclaire, who proposes that a particular trait is formed of types of multimodal perceptual fragments, that act as markers for experiences in the past that had a certain type of affective intensity, and which are recalled through action of the trait (Leclaire 1998). Traits, therefore, mark the phenomenological genesis of what are called "drives" in traditional psychoanalytic metapsychology. They originate in the work of Freud where they are termed der einzige Zug. The original reference is to the memory of a particular coloured garment, a yellow dress: "Yet I can remember quite well for what was a long time afterwards I was affected by the yellow color of the dress she was wearing when we first met, whenever I saw the same color anywhere else" (Freud 1975: 311-312). Here the experience of affective intensity is "marked" by a visual fragment, in this case a certain colour, that retains its significance for the subject long after 
the event in question. Freud and Leclaire thus connect phenomenology with the structural aspects of signification. An object or event, first encountered in an initial moment of affective intensity, provides a purely random, contingent trait whose imprint thereafter functions structurally as a kind of privileged signifier. Similarly, in a reciprocal fashion, the trait thus engendered exercises a power of determination over subsequent object choices (recall Freud's remark about how the "trait" of the yellow dress altered his subsequent colour perceptions and preferences): "A frozen moment of the individual's experience becomes elevated into a transexperiential template, a coordinate establishing a range of eidetic variations for a given drive" (Johnston 2005: 353).

This latter aspect of trait recollection/activation is something that we have found widely in participant observation. The idiomatic activity of arts participation often occurs across sensory modalities: music is accompanied by gesture, or in reference to a painting or piece of text. A certain qualitative aspect of a piece of music, for example, can trigger the recollection of a completely different perceptual scene or activity. Arts participation invokes with certain types of visual, auditory and kinesthetic information, and specifically with activities that organise themselves through experiences that manifest themselves in these different types of perceptual modalities; the proximity of the activity to a particular trait can trigger the actualisation of perceptual fragments from the past of the individual.

A striking iteration of this process was documented in one "Dance for Health" participant's experience of the devising activity based around the Kandinsky painting. The group was asked to explore solo improvisatory responses to the painting, accompanied by a range of different music. Movement across the group varied greatly, with some engaged in more playful and dynamic movements, opting for leaps and mischievous interaction with other dancers, while others opted for more a reflective and slower-paced physical response. One participant's diary entry discussing this session recorded an unexpectedly powerful sensory and emotional response to this improvisation activity, with the "catalyst" described as a streak of colour found within the painting: 
International Journal of Ageing and Later Life

The participant went on to describe the unexpected recovery, or "unconcealment" of buried pleasure concerning a past relationship, which the diary entry suggests was first manifest in her spontaneous movement within the session, then, as the memory itself sedimented, inspired direct associations with a past encounter of particular affective intensity:

Sorry if I embarrassed people and went too far [in the improvisation], but I enjoyed it enormously. Didn't look at the clock but did feel incredibly tired and went to bed after lunch, wanting to think of a long and special relationship that had to end.

An interaction between two participants in the programme's "All Singing All Dancing" similarly highlighted the potency of colour as "aesthetic trait." During a particular session, the group had worked on an intense voice and movement improvisation, creating a series of movements and a vocal soundscape exploring the sound and meaning of the ocean. The dance practitioner had provided several large expanses of blue silk which had proved particularly evocative of the roll of the waves while also facilitating notably close contact among group members, the cloths initiating a series of passing, tugging and enveloping movements. At the close of the session, participant $\mathrm{N}$ draped herself with the cloth in the form of a veil and, as discussion ensued following the end of the activity, appeared reluctant to disengage from the cloth unlike other group members who had been interacting with different pieces of material. Another participant laughingly noted how much participant $\mathrm{N}$ looked like "Mary" and asked if she'd ever played this part in the nativity, to which N replied wryly: "No. Never. That's why I'm here now."

\section{Virtual Selves}

The third form of temporal connection articulated by participants can be linked to the concept of "virtual" selves. Several participant commentaries on sessions placed an emphasis on shifting perceptions of "self," each enacting an intriguing slippage in the boundaries between past and present by stating, for example: "It's like returning to a new self"; "This class is a door back to yourself"; "It's connected me to a younger self. I wasn't a dancer then, but I suppose I am now."

The capacity of arts activity to prompt participants to create and reflect on "possible" selves (Markus \& Nurius 1986) is discussed in depth by 
Creech et al. (2014), with a particular focus on the role of music-making in the lives of older adults. Drawing on data collected as part of the "Music for Life" project, it was found that such arts activities offered project participants the means to formulate well-understood and esteemed versions of their possible future selves, including redefining an individual's identity as "a musician" or rediscovering a lost musical self. In turn, these possible selves were found to assist participants to "navigate the process of ageing in later life with enhanced subjective well-being," including a sense of purpose, autonomy and social affirmation (2014: 32). However, the theory of "future" possible selves also involves a close interaction between past and present conceptions of self. A critical element of Markus and Nurius' account is the idea that possible selves may be derived from past selves where, for instance, participants draw on past experiences in conjuring future alternatives, or rediscover "lost" possible selves in their activity in the present. $^{2}$

While this notion of "possible selves" chimes to some extent with the participant commentaries listed above, it does not fully address the complexity of a statement such as "returning to a new self." The phrase not only invokes the idea of the past ("returning") but crucially sees the past itself as constructed afresh in the present, now with new qualities ("new self") thereby extending Markus and Nurius' more linear, cumulative conception of "possible selves." The work of Henri Bergson and his notion of the "virtual" provides a helpful theoretical framework in order to account for this more slippery, instinctual approach to an individual's chronology. Bergson's Time and Free Will (1910 [1889]) outlines a radical reimagining of time, rejecting the singularity of a mechanistic, linear account of temporality to propose the possibility of "real duration" (durée réelle), a dynamic and non-linear form of "inner" time which is "a wholly

\footnotetext{
2 "Past selves, to the extent that they may define an individual again in the future, can also be possible selves. An adult, for example, will never be an 8-year-old child again. Some critical aspects of the child self, however, may remain within the selfconcept as a possible self ... and under some circumstances, this self-view may be activated and become influential in directing behavior, such as in a visit home over the holidays" (Markus \& Nurius 1986: 955).
} 
International Journal of Ageing and Later Life

qualitative multiplicity, an absolute heterogeneity of elements which pass over into one another" (Bergson 1910 [1889]: 229). ${ }^{3}$

In turn, this fluid conception of temporality is closely connected to the notion of the "virtual." Here the "virtual" is placed in contrast to the "possible": where any account of the possible is determined by its being real or not, whereas, "the virtual is not opposed to the real; it possesses a full reality by itself" (Deleuze 1994: 211). The participant commentaries presented above therefore do not suggest that the individuals concerned consider themselves to have been dancers in the past in any real or "possible" sense, but rather that their present experiences have engendered "virtual past selves" where each individual can reimagine themselves as having been a dancer. ${ }^{4}$ This idea of virtual potentialities, as afforded by a Bergsonian reading of time as a intrinsically subjective "duration," is encapsulated by Grosz (2005: 4): "Duration is that which undoes as well as what makes: to the extent that duration entails an open future, it involves the fracturing and opening up of the past and the present to what is virtual in them, to what in them differs from the actual, to what in them can bring forth the new".

As such, the present and a series of non-representational, "virtual" pasts are in a constant state of intermingling, of mutual reconstruction. However, according to Bergson (and Deleuze) this bridging of past and present is not arbitrary. For a "virtual memory" (such as having once been a dancer) to be animated or "actualised" in the present, it requires a certain catalyst: "It is the past itself that seeks to come into the present, to be actualised and made conscious, i.e. to be remembered. But since not all of the past

\footnotetext{
${ }^{3}$ This intersecting relationship between past and present is neatly summarised by Deleuze (1988: 59) in Bergonism: "the past and the present do not denote two successive moments, but two elements which coexist: one is the present, which does not cease to pass, and the other is the past, which does not cease to be, but through which all presents pass".

${ }^{4}$ Work by Cooper and Thomas (2002) on social dance among older people presents an interesting adjunct to this theoretical approach. The authors suggest how dance might allow the construction of certain "mythic" conceptions of self, suggesting that dance mitigates the public invisibility of the older person and demonstrating that old age does not have fixed consequences but allows real and mythic experiences of aliveness, fitness, fun and flexibility.
} 
Beyond health and well-being

can be actualised in each perception and since 'the choice is not made at random' (Bergson 1990: 102, 112), something else must be at play attracting certain memories and certain planes of memory rather than others" (Al-Saji 2004: 214).

Our research indicates that the specifically affective properties of artistic practice are central to this "actualisation." As an example, an intriguing group enactment of this process occurred during an "All Singing All Dancing" session. The vocal practitioner had brought in the following section of text from Allen Ginsberg's An Eastern Ballad (1945-1949).

I never dreamed the sea so deep,

The earth so dark; so long my sleep,

I have become another child.

I wake to see the world go wild.

The group were taught this text, set to a simple melody and accompanied by a pre-recorded vocal soundscape evoking sounds of the sea and delicate drone-like textures (composed by the session's facilitator). Although at the time the session facilitator was unaware of the researchers' interests in Bergsonian virtual memory, the extract (particularly line 3) can be seen to chime closely with the idea of "returning to a new self" and participants, facilitators and researchers each later agreed that the piece sparked an unexpectedly strong emotional and creative response among the group.

In the session, once participants were familiar with the melody they spread out across the space and began to add improvised gestures and free repetitions of certain words and phrases. It was notable that on the first rendition of the song (accompanied by the recorded soundscape), the words "wake" and "wild" were each spontaneously accompanied by a series of dramatic "opening" or "flowering" hand gestures among group members, while the words "I wake" (sung to a rising perfect fifth) inspired a brief calland-response configuration which looped between two participants. On the subsequent repetition of the melody, group members opted to linger on the words "I have become." Sung to a simple descending scale, "I have become" was repeated a number of times, with several participants choosing to sing the line in free-meter, creating a vivid wash of sound. In this brief exercise, the group seemed spontaneously to enact the creation of "virtual past selves": participants began by "waking" and exploring a "wildness" of expression 
International Journal of Ageing and Later Life

(one participant even commented afterwards that "I think we were trying to connect again with a certain wildness in ourselves") from which a new state of "becoming" could unfold, evident in the spontaneous flurry of vocal invention that occurred during the sung line "I have become [another child]."

Informal discussion following the exercise highlighted how affecting the exercise proved for participants and how the text, when sung and moved to, seemed to capture and intensify this idea of reimagined but intimately connected pasts, presents and futures. One participant remarked how she had felt as though "we were shipwrecked. Lying out on the shore, crawling, and we were slowly coming back to life .... The images were so powerful ... they had a tremendous sort of momentum." Another group member highlighted the sense of agency and possibility initiated for him through the text and its embodied performance: "I was singing the wrong words briefly - I sang 'gone wild' which is when you suddenly wake up and everything is changed. But 'go wild' ... that's waking up to find you're the one changing the world."

The process of "returning to a new self," where a "past self" can be remade and then "activated" in the present was evident both through participant commentary and through observation of creative work occurring in sessions. Our findings indicate that the particularly affective properties of artistic practice can offer a powerful prompt in actualising potential, virtual memories as theorised above, and that these, taken together with the types of transexperiential linkage given by recollection and trait activation, motivates what follows in the next section: an account of the intrinsic meaning of arts participation.

\section{Pragmatist Accounts of Meaning and Well-Being}

We want now to create some connections between the temporal aspects of arts participation, as defined above, and some related ideas in pragmatist philosophy. In the latter, and particularly in the work of William James and John Dewey, we see a different experiential theory of "meaning" which contrasts with the often undetermined invocations of "meaning" and "meaning-making" used in contemporary arts impact studies, while also providing us with a theoretical template for analysing the catalyst and process whereby meaning is constructed. This reformulated account of philosophical meaning stresses the common selections, or "cuts" that we 
make out of the flux of perceptual experience that end up as privileged signifiers: "we identify parts of the 'much-at-oneness' of our perceptual experience and mark them for use in understanding and transforming our past, present and future experiences" (Johnson 2008: 89).

These selections relate to things that matter to us emotionally, things that have value and significance, such as various qualities, shapes and relations (or, we could add, the colour of Freud's remembered dress). These have less to do with propositional or conceptual content than interconnecting qualia of experience, derived from our "ontological reciprocity" with the world, that create transexperiential networks of significance, linking past and present experience. It is these aspects that motivate the following definition of the intrinsic meaning of a particular activity like participation in arts activities. This type of meaning is embodied, rather than conceptual and/or propositional, and stresses, according to Mark Johnson: "the mostly nonconscious aspects of a person's ability to meaningfully engage with their past, present, and future environments ... the meaning of a thing is its consequences for experience - how it 'cashes' out by way of experience, actual or possible experience ... things and events have meaning by virtue of the way they call up something beyond them to which they are connected" (Johnson 2008: 10; 268-9). Given this pragmatist definition, we can now see why arts participation in particular can act as a privileged producer of such forms of intrinsic meaning. Arts participation, as we have observed, provides heightened, intensified and highly integrated sources of experiences that can occasion links between a participant's past, present and future experience.

This series of linkages also appears to hold a particular charge for the older people consulted: from a delight in activities occasioning sensations of "pure play, as with children" (in one participant's words) to the value of "bringing all our life experience to [the classes]." In discussion, many participants themselves chose to ascribe a particular value to these experiences based to some degree on their age. One participant from the All Singing All Dancing group remarked on the idea that:

We've been grandparents and we've been children .... Our memory is who we are. We have our bank of memories and they can train the images which feed our imagination when we're doing something improvised. And I mean, memory is not at 
International Journal of Ageing and Later Life

all fixed - it's being worked on all the time. And something like this [class] frees it all up - loosens something within - puts you in a different place.

Another participant also commented on the critical value of creative expression in developing this sense of connection and "awareness," in contrast to interventions focused solely on improving individuals' physical health. Indeed, this participant commented how it was only through accruing a certain quantity of life experience that saw her understand this difference:

\footnotetext{
You walk past [the local health centre] and you see them all on the machines - it's all about "keep fit," it's all about repetition. It's not about quality and not about self expression and not about awareness. It's so sad that the world is so mechanised. They say, "my body's a machine" but I know it's not that ... because we've lived a few decades, we know that.
}

The significance of these transexperiential connections between past, present and future for participants, expressed both in participants' own accounts and in observation of creative participation, thus suggests that such arts activity can give rise to complex and highly enriching experiences that far transcend the matrices of well-being surveys and other potentially reductive accounts of "meaning."

\title{
Concluding Thoughts: Some Ethical Considerations
}

\begin{abstract}
Enter upon this road of abstraction and the time is sure to come when the appropriate object-of-knowledge is stripped of all that is immediate and qualitative, of all that is final, self-sufficient. Then it becomes an anatomized epitome of just and only those aspects which are of indicative and instrumental import. (Dewey 1925: 106; quoted in Johnson 2008: 270)
\end{abstract}

The above quote from John Dewey's Experience and Nature (1925) is a useful way of concluding this article. As discussed earlier, many current attempts to measure participant benefit in the participatory arts among older people have focused on factors such as health and well-being that can clearly be described as "instrumental" under Dewey's proposal. Whilst we have also stressed that these approaches have contributed much to the discipline, they perhaps do not provide the whole story. 
The immediate and qualitative properties of participatory arts activities for older people, through the arts animating new and invigorating forms of temporal perception and through the embodied and intrinsic meaning of such participation, have not received the attention they perhaps deserve. We propose that evaluative methodologies in such participatory arts settings may need to adjust to include not just biomedical factors and the quantitative measurement of well-being (and other hedonic aspects) but dimensions that relate to the rich, embodied meaning of the activity itself. This meaning, owing to its singular and personal nature, is less amenable to generalisation, and any attempt to enact such abstraction or generalisation perhaps always does some damage to the actual object of study. This would perhaps necessitate methods of evaluation that allow activity to be "shown" rather than "abstracted," which provide a stronger platform for participants' own reflections and which in turn celebrate the complexity and nuance of such interactions. In an era when funding bodies are increasingly demanding more and more quantifiable mechanisms for the justification of benefit for activities like older people's participatory arts programmes, Dewey's words, written now almost a century ago, still resonate. Sources of documentation perhaps need to change to include more qualitative evidence such as personal testimony, film footage and the products of the activity itself (music, dances, visual artworks and poetry) that is left in its idiomatic setting. A balanced approach to evaluative methodologies can reflect the experiential richness of the participatory arts activities, and their benefit to participants, which far transcends the empirically quantifiable.

\section{Acknowledgements}

Sincere thanks are due to the many project participants and session facilitators for participating in numerous interviews, discussions and observed sessions.

\section{Corresponding Author}

Kate Wakeling, Trinity Laban Conservatoire of Music and Dance, Laban, Creekside, London SE8 3DZ, UK. Email: k.wakeling@trinitylaban.ac.uk 
International Journal of Ageing and Later Life

\section{References}

Allison, T. A. (2010). The nursing home as village: Lessons from ethnomusicology. Aging, Humanities and the Arts 4(3): 276-291.

Al-Saji, A. (2004). The memory of another past: Bergson, Deleuze and a new theory of time. Continental Philosophy Review 37(2): 203-239.

Aspinwall, L. \& Standinger, U. M. (2003). Towards a Psychology of Human Strengths. Washington, DC: APA Books.

Ateca-Amestoy, V. \& Ugidos, A. (2013). The impact of different types of resource transfers on individual wellbeing: An analysis of quality of life using CASP-12. Social Indicators Research 110(3): 973-991.

Baker, F. \& Intagliata, J. (1982). Quality of life in the evaluation of community support systems. Evaluation and Program Planning 5: 69-75.

Bedding, S. \& Sadlo, G. (2008). Retired people's experience of participation in art classes. British Journal of Occupational Therapy 71: 371-378.

Bergson, H. (1910 [1889]). Time and Free Will: An Essay on the Immediate Data of Consciousness. London: George Allen and Unwin.

Bergson, H. (1990 [1896]). Matter and Memory. New York: Zone Books.

Bernet, R. (2009). Husserl's early time-analysis in historical context. Journal of the British Society for Phenomenology 40(2): 117-154.

Bowling, A., Banister, D., Stenner, P., Titheridge, H., Sproston, K. \& McFarquhar, T. (2009). Quality of life in older age: Psychometric testing of the multidimensional older people's quality of life (OPQOL) questionnaire and the causal model under-pinning it. (Project Report). Sheffield, UK: University of Sheffield.

Castora-Binkley, M., Noelker, L., Prohaska, T. \& Satariano, W. (2010). Impact of arts participation on health outcomes for older adults. Journal of Aging, Humanities $\mathcal{E}$ the Arts 4(4): 352-367.

Cohen, G. D. (2006). Research on creativity and aging: The positive impact of the arts on health and illness. Generations 30(1): 7-15.

Cohen, G. D., Perlstein, S., Chapline, J., Kelly, J., Firth, K. M. \& Simmens, S. (2007). Impact of professionally conducted cultural programs on the physical health, mental health, and social functioning of older adults 2-Year results. Journal of Aging, Humanities and the Arts 1(1-2): 5-22.

Connolly, M. \& Redding, E. (2010). Dancing towards well-being in the third age: Literature review on the impact of dance on the health and well-being of older people. London: Trinity Laban Conservatoire of Music and Dance. 
Cooper, L. \& Thomas, H. (2002). Growing old gracefully: Social dance in the third age. Ageing \& Society 22(6): 689-708.

Creech, A., Hallam, S., Varvarigou, M., Gaunt, H., McQueen, H. \& Pincas, A. (2014). The role of musical possible selves in supporting subjective well-being in later life. Music Education Research 16(1): 32-49.

Creech, A., Hallam, S., Varvarigou, M., McQueen, H. \& Gaunt, H. (2013). Active music making: A route to enhanced subjective well-being amongst older people. Perspectives in Public Health 133(1): 36-43.

Cutler, D. (2009). Ageing Artfully: Older People and Professional Participatory Arts in the UK. London: Baring Foundation.

Dabback, W. M. (2008). Identity formation through participation in the Rochester New Horizons Band Programme. International Journal of Community Music 1(2): 267-286.

Deleuze, G. (1988). Bergsonism. Trans. H. Tomlinson and B. Habberjam. New York: Zone Books.

Deleuze, G. (1994). Difference and Repetition. Trans. P. Patton. London: Athlone.

Dewey, J. (1925). Experience and Nature. The Later Works, 1925-1953 (vol. 1). Carbondale, IL: Southern Illinois University Press.

Doyal, L. \& Gough, I. (1991). A Theory of Human Need. Hampshire: Macmillan.

Erikson, E. H. \& Erikson, J. M. (1997). The Life Cycle Completed. New York: W.W. Norton.

Fisher, B. J. \& Specht, D. K. (1999). Successful aging and creativity in later life. Journal of Aging Studies 13(4): 457-472.

Freud, S. (1975). Screen memories. In J. Strachey (ed.), The Standard Edition of the Works of Sigmund Freud (vol. 3, pp. 303-22). London: The Hogarth Press.

Gilleard, C. \& Higgs., P. (2000). Cultures of Ageing. London: Prentice Hall.

Grosz, E. (2005). Bergson, Deleuze and the becoming of unbecoming. Parallax 11(2): 4-13.

Hallam, S., Creech, A., Gaunt, H., Pincas, A., Varvarigou, M. \& McQueen, H. (2011). Music for Life Project: The Role of Participation in Community Music Activities in Promoting Social Engagement and Well-being in Older People. Sheffield: NDA Research Programme. 
International Journal of Ageing and Later Life

Hays, T. \& Minichiello, V. (2005). The contribution of music to quality of life in older people: An Australian qualitative study. Psychology of Music 33(4): 437-451.

Huppert, F. A., Marks, N., Clark, A., Siegrist, J., Stutzer, A., Vitterso, J. \& Wahrendorf, M. (2009). Measuring well-being across Europe: Description of the ESS well-being module and preliminary findings. Social Indicators Research 91: 301-315.

Hyde, M., Wiggins, R. D., Blane, D. \& Higgs, P. (2003). A measure of quality of life in early old age: The theory, development and properties of a needs satisfaction model. Aging and Mental Health 7: 86-94.

Johnson, M. (2008). The Meaning of the Body: Aesthetics of Human Understanding. Chicago, IL: University of Chicago Press.

Johnston, A. (2005). Time Driven: Metapsychology and the Splitting of the Drive. Evanston, IL: Northwestern University Press.

Jonsson, H., Josephsson, S. \& Kielhofner, G. (2001). Narratives and experience in occupational transition: A longitudinal study of the retirement process. American Journal of Occupational Therapy 55(4): $424-432$.

Lally, E. (2009). 'The power to heal us with a smile and a song': Senior well-being, music-based participatory arts and the value of qualitative evidence. Journal of Arts and Communities 1(1): 25-44.

Laukka, P. (2006). Uses of music and psychological well-being among the elderly. Journal of Happiness Studies 8: 215-241.

Leclaire, S. (1998). Psychoanalyzing: On the Order of the Unconscious and the Practice of the Letter. Stanford, CA: Stanford University Press.

Lloyd-Sherlock, P., McKee, M., Ebrahim, S., Gorman, M., Greengross, S., Prince, M., Pruchno, R., Gutman, G., Kirkwood, T. \& O'Neill, D. (2012). Population ageing and health. The Lancet 379(9823): 1295-1296.

Marcia, J. E. (1966). Development and validation of ego identity status. Journal of Personality and Social Psychology 3: 551-558.

Markus, H. \& Nurius, P. (1986). Possible selves. American Psychologist 41(9): 954-969.

McFadden, S. H. \& Basting, D. (2010). Healthy aging persons and their brains: Promoting resilience through creative engagement. Clinics in Geriatric Medicine 26(1): 149-161. 
McLean, J. (2011). An Evidence Review of the Impact of Participatory Arts on Older People. Edinburgh: MHF.

Mroczek, D. K. \& Kolarz, C. M. (1998). The effect of age on positive and negative affect: A developmental perspective on happiness. Journal of Personality and Social Psychology 75(5): 1333-1349.

Noice, T., Noice, A. \& Krame, A. (2014). Participatory arts for older adults: A review of benefits and challenges. The Gerontologist 54(5): 741-53.

Peterson, C. \& Seligman, M. E. P. (2004). Character Strengths and Virtues: A Handbook and Classification. Washington, DC: APA Press.

Power, M., Quinn, K., Schmidt, S. \& Group., WHOQOL-OLD (2005). Development of the WHOQOL-old module. Quality of Life Research 14(10): 2197-2214.

Rudman, D. L., Cook, J. V. \& Polatajko, H. (1997). Understanding the potential of occupation: A qualitative exploration of seniors' perspectives on activity. The American Journal of Occupational Therapy 51(8): 640-650.

Ruokonen, I. \& Ruismäki, H. (2011). Lifelong learning and musical interaction: Integrated musical activity increases the well-being of older people'. Procedia - Social and Behavioral Sciences 12: 340-345.

Ryan, R. M. \& Deci, E. L. (2001). On happiness and human potentials: A review of research on hedonic and eudaimonic well-being. Annual Review of Psychology 52: 141-166.

Ryan, R. M., Huta, V. \& Deci, E. L. (2008). Living well: A self-determination theory perspective on eudaimonia. Journal of Happiness Studies 9(1): 139-170.

Ryff, C. (1989). Happiness is everything, or is it? Explorations on the meaning of psychological well-being. Journal of Personality and Social Psychology 57: 1069-1081.

Ryff, C. D. \& Singer, B. H. (2008). Know thyself and become what you are: A eudaimonic approach to psychological well-being. Journal of Happiness Studies 9(13): 13-39.

Shmotkin, D. (2011). The pursuit of happiness: Alternative conceptions of subjective well-being. In L. W. Poon \& J. Cohen-Mansfield (eds.), Understanding Well-being in the Oldest Old (pp. 27-45). Cambridge: Cambridge University Press.

Sinnott, J. D. (1998). Creativity and postformal thought: Why the last stage is the creative stage. In C. E. Adams-Price (ed.), Creativity and 
International Journal of Ageing and Later Life

Successful Aging: Theoretical and Empirical Approaches (pp. 43-72). New York: Springer.

Skingley, A. \& Vella-Burrows, T. (2010). Therapeutic effects of music and singing for older people and singing for older people. Nursing Standard 24(19): 35-41.

Stuckey, H. \& Nobel, J. (2010). The connection between art, healing and public health: A review of current literature. American Journal of Public Health 100(2): 254-263.

Taylor, C. (1987). Art and the needs of the older adult. Art Education 40(4): 9-15.

Thompson, E. (2010). Mind in Life. Cambridge, MA: Harvard University Press.

Twigg, J. (2004). The body, gender and age: Feminist insights in social geronotology. Journal of Aging Studies 18: 59-73.

Vincent, J. (2003). Old Age. London: Routledge.

Vittersø, J. (2004). Subjective wellbeing versus self-actualization: Using the flow-simplex to promote a conceptual clarification of subjective quality of life. Social Indicators Research 65(3): 299-331.

Watson, D., Clark, L. A. \& Tellegen, A. (1988). Development and validation of brief measures of positive and negative affect: The PANAS scales. Journal of Personality and Social Psychology 54(6): 1063-1070.

Wiggins, R. D., Netuveli, G., Hyde, M., Higgs, P. \& Blane, D. (2007). The evaluation of a self-enumerated scale of quality of life (CASP-19) in the context of research on ageing: A combination of exploratory and confirmatory approaches. Social Indicators Research 89(1): 61-77. 